\title{
Development and test verification of air temperature model for Chinese solar and Spainish Almeria-type greenhouses
}

\author{
Jorge Antonio Sanchez-Molina ${ }^{1}$, Li Ming ${ }^{2 *}$, Francisco Rodriguez ${ }^{1}$, \\ Jose Luis Guzman ${ }^{1}$, Wang Hui ${ }^{1,2}$, Yang Xinting ${ }^{2}$ \\ (1. The Automatic Control, Robotics and Mechatronics Research Group, Department of Informatics, ceiA3, CIESOL, University of Almeria, \\ Almeria 04120, Spain; 2. Beijing Research Center for Information Technology in Agriculture/National Engineering Research Center for \\ Information Technology in Agriculture/National Engineering Laboratory for Agri-product Quality Traceability/Key Laboratory for \\ Information Technologies in Agriculture, Ministry of Agriculture, Beijing 100097, China.)
}

\begin{abstract}
Growth can be defined as an increment in biomass or an increment in weight or height of the organs of the plant influenced by physiological processes. Many of these processes have their limits genetically determined, but climate and irrigation play an important role. Because of its importance, microclimate has been extensively studied in the modeling as a surrounding condition which is imposed by the exterior climate. The main objective of this work was to develop a temperature model based on the energy balance dynamics at two different greenhouse locations - South - eastern Spain and Northern China, and the traditional structures of Chinese solar greenhouse and Almería-type multi-span greenhouse were taken into account. The final model was developed by combining the external conditions, the actuator influence and the crop growth, where the temperature is influenced by soil, crop, cover, actuators, back wall and greenhouse geometry. The model took into account the energy lost by convective and conductive fluxes, as well as the energy supplied by solar radiation and heating systems. The soil and the back wall are the main media for energy storage. The temperature dynamic was determined by a physical model, which considered the energy balance from a holistic point of view - as a sub-model for a customizable interface among the external climate, the plant and the greenhouse system. The influences of different subsystems included in the temperature model were analyzed and evaluated. The results showed a high $R^{2}$ value of 0.94 for Beijing and 0.95 for Almeria, and the average error was low, of which the MAE and RMSE were 0.71 and 1.365 for Almeria and 0.62 and 1.102 for Beijing, respectively. Thus, the model can be considered as a powerful tool for control design purposes in microclimate systems.
\end{abstract}

Keywords: air temperature model, Chinese solar greenhouse, Spanish Almería-type greenhouse, energy balance dynamics, microclimate

DOI: $10.25165 / \mathrm{j}$.jjabe.20171004.2398

Citation: Sanchez-Molina J A, Li M, Rodriguez F, Guzman J L, Wang H, Yang X T. Development and test verification of air temperature model for Chinese solar and Spainish Almeria-type greenhouses. Int J Agric \& Biol Eng, 2017; 10(4): 66-76.

\section{Introduction}

The greenhouse is a complex with physical, chemical,

Received date: 2016-01-26 Accepted date: 2017-01-15 Biographies: Jorge Antonio Sanchez-Molina, PhD, Associate Professor, research on greenhouse climate and irrigation modelling and automatic control, Email: jorgesanchez@ual.es; Francisco Rodriguez, $\mathrm{PhD}$, Professor, research on greenhouse environment and crop modeling and optimization, Email: frrodrig@ual.es; Jose Luis Guzman, PhD, Professor, research on biotechnological modelling and automatic control, Email: joguzman@ual.es; Wang Hui, $\mathrm{PhD}$ candidate, research on warning system of greenhouse and biological processes taking place simultaneously, each process reacting with different response times and patterns to environmental factors, and characterized by

vegetable diseases, Email: hw646@ual.es; Yang Xinting, PhD, Professor, research on agricultural product quality safety, Email: xintingyang@nercita.org.cn.

* Corresponding author: Li Ming, Associated Professor, research on warning system of greenhouse vegetable diseases and pests, Beijing Research Center for Information Technology in Agriculture, Beijing, China. Tel: +8610-51503912, Fax: +8610-51503750, Email: lim@nercita.org.cn. 
multiple interactions, which must be controlled to obtain the best results for the grower ${ }^{[1]}$. Crop growth is mainly influenced by environmental variables and the amount of water and fertilizers supplied by irrigation. This is the main reason why a greenhouse is ideal for cultivation as it constitutes a closed environment in which climatic and fertigation variables can be controlled to allow optimal crop growth and development - the climate and the fertigation being two independent systems. Moreover, the greenhouses are exposed to great dynamism, where rapid decision making has to be performed based on several interdependent factors of an agricultural, technological, environmental, legal and economic nature. Thus, knowing and understanding these processes make it possible to improve crop production and fruit quality ${ }^{[2]}$, leading to sustainable development ${ }^{[3,4]}$. Likewise, physical and biological models can also help to understand the different processes.

Up until now, there has been a lack of physical and biological models suitably representing the temporal and spatial gradients of the main variables of the greenhouse subprocesses. The development of dynamic system models is a complex process that depends on the characteristics of the process dynamics under study. These models have to be applied to several greenhouse structures (many of which are small in size and used for research purposes), with different climatic actuators, cover materials, structures and crops. The number of equations to be solved depends on the known or measured variables; that is, on the boundary conditions ${ }^{[5]}$. Most researchers agree in adopting all the greenhouse climate disturbances as boundary conditions ${ }^{[1,6,7]}$. In the literatures, the majority of the models are based on steady state or are only focused on a particular part of the process ${ }^{[8-12]}$. There were some temperature estimation models developed in China ${ }^{[13-15]}$ or $\operatorname{Spain}^{[16,17]}$, which provided excellent background for different climate and types of greenhouse modelling. However, it is hard to find models that can meet different countries' climate based on fundamental principles and PDEs due to their great complexity and the large number of experiments required for their accurate calibration. As in other scientific fields, their mathematical representations are often developed by ordinary differential equations (ODEs). ODEs provide a mathematical description of the spatial and temporal dimensions, or the energy or mass balances involved; these being the most widely used of mathematical forms.

In addition to the energy or mass balances that take place are the transport mechanisms (conduction, convection and radiation) that describe the different processes that happen inside the greenhouse that affect climatic variables ${ }^{[18,19]}$; these are applied to all of a greenhouse's constitutive elements: cover, crop, air and soil/substrate ${ }^{[1,18,20]}$. Besides these interactions amongst the different constitutive elements, and their effect on the climate and water content, each crop has its own demand on the environment, changing with its growth state. Consequently, this growth state influences both balances, increasing system complexity. Furthermore, to comprehend all the issues that play a part in complex greenhouse behavior, models have proven themselves a potent tool in understanding the processes and in designing proper control algorithms for the different system variables of the characteristics under study ${ }^{[21,22]}$. These models allow one to simulate the dynamic behavior of the climate and fertigation variables, which is important for managing the relationships between the climatic conditions (both inside and outside the greenhouse) ${ }^{[23]}$.

Nevertheless, of all the climate and fertigation variables, temperature is one of the most influential on crop growth, and has traditionally been the most limited variable in greenhouses in Beijing, China, likewise, in south-east Spain (second only to water availability). A plant only grows under the influence of light when it performs photosynthesis; and maximum growth rates also require a relatively high temperature. At night, the crop is inactive (with no growth) so it is not necessary to maintain a high temperature. Therefore, two daily setpoints are defined, one for night-time and another higher one for daytime ${ }^{[1]}$. Due to the favorable weather conditions present in south-eastern Spain and Beijing during the day, the energy necessary to reach the optimal temperature is provided by the sun and it is not necessary to supplement it except under extreme conditions ${ }^{[24]}$. 
Temperature becomes a state variable that describes the greenhouse environment and directly affects the crop production capacity, influencing, amongst other things, crop transpiration ${ }^{[8,25]}$ and photosynthesis ${ }^{[26-28]}$. In turn, it is influenced by air exchange with the outside ${ }^{[29]}$. For this reason, the main objective of the current work is to adapt the temperature model proposed by Rodriuez et al. ${ }^{[1]}$, modifying it with new equations and with the works of Sanchez-Molina et al. ${ }^{[30]}$, all based on fundamental principles at two different greenhouses: (i) at Beijing Xiaotangshan base in China and (ii) at the Cajamar Foundation Experimental Station (in South-eastern Spain), where different subsystems were tested and real responses observed. The meteorological inputs/outputs and the actuator status data are used to calibrate such models without losing the physical meaning of the processes involved in the energy balance equations.

\section{Model development}

The greenhouse climate can be described using a dynamic model represented by a system of differential Equation given as:

$$
d X / d t=f(X, U, D, V, C, t) \text { with } X\left(t_{i}\right)=X_{i}
$$

where, $X=X(t)$ is an $n$-dimensional vector of state variables; $U=U(t)$ is an $m$-dimensional vector of input variables; $D=D(t)$ is an $o$-dimensional vector of disturbances; $V=V(t)$ is a $p$-dimensional vector of system variables; $C$ is a $q$-dimensional vector of system constants, $t$ is the time; $X_{i}$ is the known initial state at the initial time $t_{i}$ and $f=f(t)$ is a non-linear function based on mass and heat transfer balances. The number of equations describing the system and their characteristics depends on the greenhouse elements, the installed control actuators and the type of cultivation method (Figure 1).

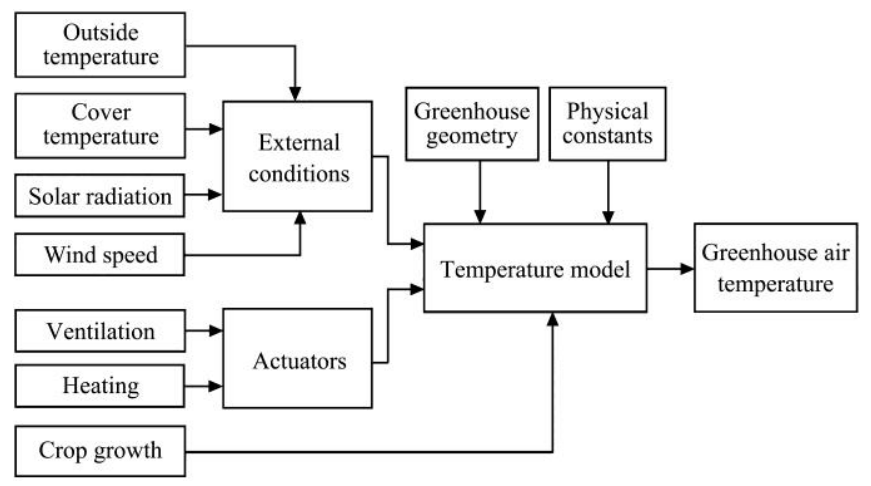

Figure 1 Temperature model scheme

\subsection{General temperature model}

$$
\begin{aligned}
& c_{s p h, a} c_{d e n, a}\left(c_{v o l, g} / c_{\text {area }, s}\right) d X_{T, a} / d t= \\
& Q_{c n v, c v-a}+Q_{c n v, s s-a}-Q_{v e n}-Q_{t r p, c r}
\end{aligned}
$$

where, $Q_{c n v, c v-a}$ is the convective flux with the cover; $Q_{c n v, s s-a}$ is the convective flux with the soil surface; $Q_{v e n}$ is the heat lost by natural ventilation and the heat lost by infiltration losses; $Q_{t r p, c r}$ is the latent heat effect from crop transpiration, and $\left(c_{s p h, a c d e n, a}\right)=\left(c_{v o l, g c a r e, s}\right)$ is the product of specific air heat, the air density and the effective height of the greenhouse (the greenhouse volume and soil surface area).

\subsubsection{Convective flux with the cover $\left(Q_{c n v, c v-a}\right)$}

The convective heat transfer from the inside air to the cover is calculated based on the difference between the cover temperature, $X_{t, c v}$, and the greenhouse air temperature, $X_{t, a}{ }^{[1]}$ :

$$
Q_{c n v, c v-a}=V_{c n v, c v-a}\left(c_{\text {area }, c v} / c_{\text {area }, s s}\right)\left(X_{T, c v}-X_{T, a}\right)
$$

where, $V_{c n v, c v-a}$ is the cover's inside convective heat transfer coefficient based on the difference between the model, the approach proposed by $\mathrm{Ha}$ et al. ${ }^{[31]}$ has been used: if the internal air temperature is higher than the cover temperature, the heat transfer is turbulent; otherwise the heat flux is laminar; $c_{\text {area,cv }}$ is the cover surface and $c_{\text {area,ss }}$ is the soil surface.

\subsubsection{Convective flux with the soil surface $\left(Q_{c n v, s s-a}\right)$}

The convective heat transfer from inside air to soil surface is calculated in the same way as the cover convective fluxes using the following equation ${ }^{[1]}$.

$$
Q_{c n v, s s-a}=V_{c n v, s s-a}\left(X_{T, s s}-X_{T, a}\right)
$$

where, $V_{c n v, s s-a}$ is the inside soil surface convective heat transfer coefficient based on the difference between the soil surface temperature and the internal air temperature, and the mean greenhouse air speed over the soil surface. Using the studies ${ }^{[32]}$, the conductive flux between the soil surface and the first soil layer is calculated based on the assumption that the heat flux is one-dimensional ( $Z$ axis).

\subsubsection{Heat lost by natural ventilation and infiltration} $\left(Q_{\text {ven }}\right)$

The heat lost by natural ventilation term is modelled according to ASAE standard EP406.3 $3^{[33]}$ as a function of flow rate, greenhouse temperature $\left(X_{t, a}\right)$ and external wind velocity $\left(D_{t, e}\right)^{[34]}$ :

$$
Q_{\text {ven }}=V_{\text {ven,flux }}\left(c_{\text {den, } a} c_{\text {sph,a }} / c_{\text {area }, \text { ss }}\right)
$$


where, $V_{\text {vent,flow }}$ is the volumetric flow rate described in Equation (6) and $V_{\text {texh,a }}$ is the exhaust air temperature, calculated as a linear combination of external and internal air temperature ${ }^{[35]}$. This term includes the heat lost by infiltration losses, as shown in the volumetric flow rate equation, which is based on the thermal buoyancy and wind forces and is described as:

$$
\begin{gathered}
V_{\text {ven }, \text { flux }}=c_{\text {ven }, n}\left(c_{\text {ven }, l} c_{\text {ven,d }} V_{\text {ven,hef }} / 2\right)\left[c_{g}\left(V_{\text {ven,hef }} / 2\right)\right. \\
\left.\left(\left(X_{T, a}-D_{T, e}\right) / D_{T, e}\right)\right]^{0.5}+\left(c_{v e n, w d} 0.5 D_{w s, e}\right]+V_{\text {loss }}
\end{gathered}
$$

where, $c_{v e n, n}$ is the number of vents; $c_{v e n, l}$ is the length of the vents; $c_{v e n, d}$ is the discharge coefficient; $c_{g}$ is the gravity constant; $c_{v e n, w d}$ is the wind-effect coefficient; $V_{v e n, h e f}$ is the cord joining the two extremities of the vent based on the position of the vent; $U_{v e n}$ using the following equation:

$$
V_{v e n, h e f}=2 c_{v e n, w} \sin \left(U_{v e n} / 2\right)
$$

where, $c_{\text {ven,w }}$ is the width of vent $V_{\text {loss }}$ is the leakage when the vent is closed, based on the external wind speed $\left(D_{w s, e}\right)$ :

$$
\begin{aligned}
& V_{\text {loss }}=c_{\text {loss }, \text { w }} \text { when } D_{w s, e}<c_{w s, l i m} \\
& V_{\text {loss }}=c_{\text {loss, } h w} \text { when } D_{w s, e} \geq c_{w s, l i m}
\end{aligned}
$$

where, $c_{w s, l i m}$ is the wind speed, considered as the limit between high and low wind speeds.

\subsubsection{Latent heat effect of the crop transpiration $\left(Q_{t r p, c r}\right)$}

The crop itself affects the greenhouse air temperature. As no leaf area measurements are available, it is not possible to use a convective factor in the heat balance equation functioning as a boundary variable. One way to model the effect of the crop on the air temperature is based on the latent heat caused by plant transpiration, described by the following equation ${ }^{[30]}$ :

$$
Q_{t r p, c r}=V_{l t, v a p} M_{t r p, c r}
$$

where, $M_{t r p, c r}$ is the crop transpiration. Most transpiration estimators are based on the Penman-Monteith Equation $^{[8,30]}$. This equation essentially combines the heat transfer equation between the crop and the surrounding air mass. A simplified pseudophysical transpiration model can be used, based on two main variables: the solar radiation (VSR) arriving at a particular depth in the plant canopy and the vapour pressure deficit $^{[30]}$ :

$$
M_{t r p, c r}=c_{A} e^{-c} k X_{L A I} V_{G R}+c_{B} X_{L A I} V_{V P D}
$$

where, $V_{l t \text {,vap }}$ is the latent heat of evaporation; $c_{k}$ is the light extinction coefficient for the crop (this is related to the leaf inclination angle and the leaf arrangement with regard to the leaf area index (LAI), and provides an indication of the plant's efficiency at intercepting solar radiation); $X_{L A I}$ is the LAI; $V_{V P D}$ is the vapor pressure deficit, and $V_{G R}$ is the global radiation reaching the crop. The coefficients $c_{A}$ and $c_{B}$ are constants dependent on the crop. To obtain more reliable results, the parameter $c_{B}$ is obtained for diurnal $\left(c_{B D}\right)$ and nocturnal $\left(c_{B N}\right)$ periods through calibration.

\subsection{Beijing's greenhouse - specific processes}

The greenhouse air temperature is modified for the Chinese solar greenhouse by adding two equations, $Q_{\text {evp,ss }}$ is the latent heat effect of evaporation in the soil and $Q_{c n v, \text { wall-a }}$ is the convective flux with the back wall, to the energy balance:

$$
\begin{aligned}
& c_{s p h, a} c_{d e n, a}\left(c_{v o l, g} / c_{\text {area }, s}\right) d X_{T, a} / d t=Q_{c n v, c v-a}+Q_{c n v, s s-a}+ \\
& Q_{c n v, \text { wall-a}}-Q_{v e n}-Q_{t r p, c r}-Q_{\text {evp }, s s}
\end{aligned}
$$

\subsubsection{Convective flux with the back wall $\left(Q_{c n v, \text { wall-a }}\right)$}

The convective heat transfer from the inside air to the back wall is calculated in the same way as for the soil convective fluxes:

$$
Q_{c n v, \text { wall-a }}=V_{c n v, \text { wall-a }}\left(X_{T, \text { wall }}-X_{T, a}\right)
$$

where, $V_{c n v, \text { wall-a }}$ is the inside back wall convective heat transfer coefficient based on the difference between the wall temperature and the internal air temperature, and the mean greenhouse air speed on the wall surface. As for the wall surface itself, the studies of [32] were used:

$$
V_{c n d, \text { wall-a }}=\left[c_{c n v, \text { wall-a }}\left|X_{T, \text { wall }}-X_{T, a}\right| c^{c n v, \text { wall-a2 }}\right] c^{c n v, \text { wall-a3 }}(13
$$

where, $c_{c n v \text {,wall-aX }}$ are empirical parameters that have to be estimated. As with the soil surface, the conductive flux between the wall surface and the deepest wall layer is calculated based on the assumption that the heat flux is one-dimensional ( $Z$ axis):

$$
Q_{\text {cnd,wall,wall } 1}=c_{c n d, \text { wall } 1}\left[\left(X_{T, \text { wall }}-X_{T, \text { wall } 1}\right) /\left(c_{d, \text { wall } 1}-c_{d, \text { wall }}\right)\right]
$$

where, $c_{c n d \text {,wall } 1}$ is the heat conductivity of the first wall layer; $c_{d, \text { wall }}$ is the wall surface depth; $c_{d, \text { wall } 1}$ is the first wall layer thickness and $X_{t, \text { wall } 1}$ is the deepest layer temperature, considered constant at the average yearly outside temperature.

\subsubsection{The latent heat flux at the soil surface $\left(Q_{\text {evp,ss }}\right)$}

The latent heat at the soil surface is mainly produced by evaporation; it is calculated as a convective flux using 
the following equation ${ }^{[1]}$ :

$$
Q_{e v p, s s}=V_{l t, v a p} M_{l t, s s}
$$

where, $M_{\text {evp,ss }}$ is the mass evaporation flux from the soil surface, which can be obtained by:

$$
M_{e v p, s s}=c_{d e n, a}\left(V_{c n v, s s-a} / C_{s p h, a}\right)\left(V_{h s a t, s s}-X_{h a, a}\right)
$$

where, $X_{h a, a}$ is the outside average yearly temperature used as the temperature for the internal soil layer.

\subsection{Almeria's greenhouse - specific processes}

In this case, the greenhouse air temperature was modified by adding two equations to the energy balance:

$$
\begin{aligned}
& c_{s p h, a} c_{d e n, a}\left(c_{v o l, g} / c_{\text {area }, s}\right) d X_{T, a} / d t=Q_{c n v, c v-a}+ \\
& Q_{c n v, s s-a}+Q_{c n v, \text { heat }-a}-Q_{v e n}-Q_{t r p, c r}
\end{aligned}
$$

where, $Q_{c n v, \text { aero-a }}$ are the heat fluxes with the pipe-based heating systems and $Q_{c n v, h e a t-a}$ are the heat fluxes with the aerothermal heating system.

2.3.1 Heat fluxes with the pipe-based heating systems $\left(Q_{c n v, \text { heat-a }}\right)$

Depending on the heating system, the model used has to vary. In the case of heating pipes, the heat transfer is produced by convective heat fluxes with the pipes. It is calculated by considering the hot water temperature to be similar to the temperature of the pipes' external surfaces, neglecting the effect of the convective flux between the hot water on the internal heating pipe surfaces and the pipes' conductive flux. This term is given by the following equation ${ }^{[1]}$ :

$$
Q_{c n v, \text { heat }-a}=V_{c n v, \text { heat }-a}\left(c_{\text {area, heal }} / c_{\text {area }, s s}\right)\left(U_{T, \text { heat }}-X_{T, a}\right)
$$

where, $U_{t, \text { heat }}$ is the water temperature entering the heating pipes and $V_{c n v, \text { heat-a }}$ is the heating's convective heat transfer coefficient calculated in the same way as the other convective coefficients:

$$
\begin{aligned}
& V_{c n v, \text { heat }-a}=c_{c n v, \text { heat }-a 1}\left|\left(U_{T, \text { heat }}-X_{T, a}\right) / c_{c l, \text { heat }}\right|^{c_{\text {cnv, heat }-a 2+}} \\
& {\left[V_{w s, \text { axx }}\left(c_{c n v, \text { heat }-a 4} D_{L A I}\right)\right]^{c}{ }^{c n v, \text { heat }-a 5}}
\end{aligned}
$$

2.3.2 Heat fluxes with aerothermal heating systems $\left(Q_{c n v, \text { aero-a }}\right)$

In this case, the energy is supplied by an air heating system. Supposing the heating system is perfectly linear with respect to the control signal $U_{t, \text { heat }}$, it can be assumed that ${ }^{[1]}$ :

$$
Q_{\text {cnv, heat-a }}=Q_{\text {heat,en }} c_{\text {heat,ef }} U_{\text {T,heat }}
$$

where, $Q_{c a l, e n}$ is the nominal energy of the heating system; $C_{c a l, e f}$ is its efficiency coefficient; $Q_{\max }=Q_{c a l, e n} C_{c a l, e f}$ is the maximum energy that can be contributed by the system and $U_{a c, \text { heat }}$ is the heater activation control signal.

2.3.3 Modification of the heat lost by natural ventilation and infiltration $\left(Q_{v e n}\right)$

Where the greenhouse has lateral and roof ventilation, the following proposal can be used by [29] and modified by [34]:

$$
\begin{aligned}
& V_{\text {ven,flux }}=c_{\text {ven, } d}\left[\left(V_{\text {ven,area-lat }} V_{\text {ven,area-roof }} /\left(V_{\text {ven,area-lat }}{ }^{2}+\right.\right.\right. \\
& \left.\left.V_{\text {ven,area-roof }}\right)^{2} \cdot\left(2 c_{g} c_{\text {ven, } h}\left(X_{T, a}-D_{T, e}\right) / D_{T, e}\right)\right)+ \\
& \left.\left.\left(V_{\text {ven,area-lat }} V_{\text {ven,area-roof }} / 2\right)\right)^{2} c_{\text {ven,wd }} D_{w s, e}\right]^{0.5}+V_{\text {loss }}
\end{aligned}
$$

where, $V_{\text {ven,area-lat }}$ and $V_{\text {ven,area-roof }}$ are the areas of the roof and sidewall ventilation openings, given by the following Equations:

$$
\begin{gathered}
V_{\text {ven,area-lat }}=c_{\text {ven,l-lat }} c_{\text {ven,w-lat }}\left(U_{\text {ven }} / 100\right) \\
V_{\text {ven,area-roof }}=2 c_{\text {ven,l-roof }} c_{\text {ven, }, \text {-lat }} \sin \left(U_{\text {ven }} / 100\right)\left(U_{\text {ven, } \max } / 2\right)
\end{gathered}
$$

where, $c_{\text {ven,long-lat }}$ and $c_{\text {ven,long-roof }}$ are the lateral and roof lengths respectively; $c_{\text {ven,wid-lat }}$ and $c_{\text {ven,wind-roof }}$ are the lateral and roof widths, and $U_{v e n}$ is the ventilation opening percentage.

\section{Materials and methods}

\subsection{Test greenhouses and measurements}

\subsubsection{Solar greenhouse in China}

This study was conducted from August to December, 2014 and a solar greenhouse at Beijing Xiaotangshan base, in Changping district, Beijing, China $\left(40.18^{\circ} \mathrm{N}\right.$, $116.47^{\circ} \mathrm{E}$ ). The greenhouse (with a north-south orientation, Figure 2) is $350 \mathrm{~m}^{2}$ ( $50 \mathrm{~m}$ length $\times 7 \mathrm{~m}$ width). A Davis Vantage Pro \& Plus meteorological station was located outside the greenhouse to measure meteorological data. Inside greenhouse, we collected data including soil temperature, air temperature and humidity, solar radiation, net radiation, wall and covering temperature.

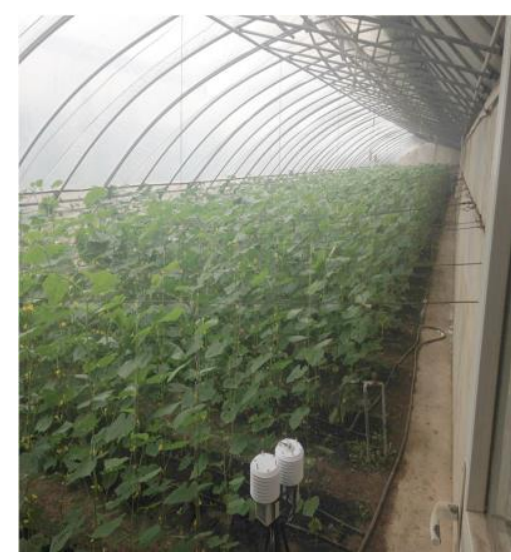

Figure 2 Solar greenhouse in Changping district, Beijing, China 


\subsubsection{Multi-span greenhouse in South-eastern Spain}

The data used in this research was acquired from the Cajamar Foundation Experimental Station greenhouses in El Ejido, Almeria Province, Spain $\left(2^{\circ} 43^{\prime} \mathrm{W}, 36^{\circ} 48^{\prime} \mathrm{N}\right.$, and 151 m a.s.l.) between August 2010 and May 2014. The crops grew in a multi-span 'Parral-type' greenhouse (Figure 3). The greenhouse is $877 \mathrm{~m}^{2}(37.8 \mathrm{~m} \times 23.2 \mathrm{~m})$ with a variable height (between 2:8 $\mathrm{m}$ and $4: 4 \mathrm{~m}$ ) with a polyethylene cover. Most of collected data is similar with Chinese greenhouse. In this greenhouse, there are automated ventilation with windows, a heating system, a dehumidification system and a biomass-based system.

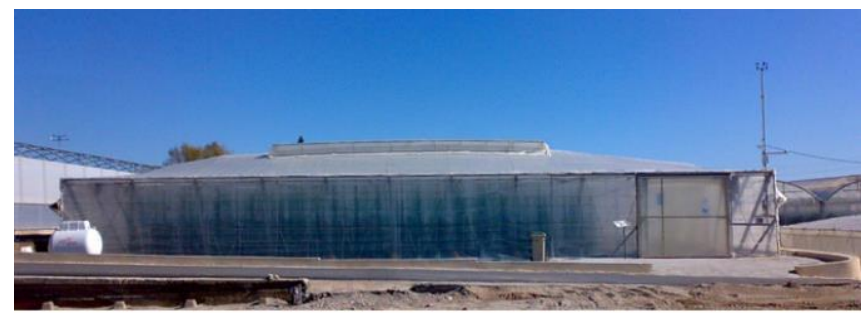

a. Greenhouse

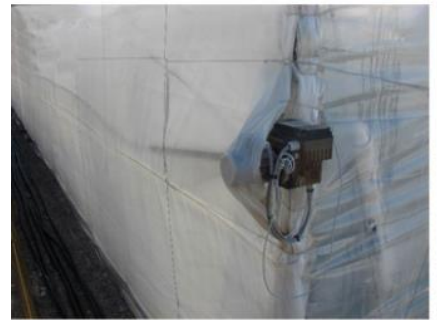

b. Side windows with anti-insect screen and the engine

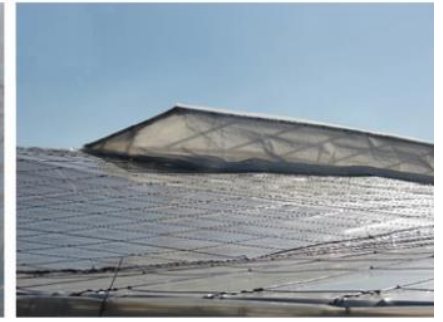

c. Roof windows with anti-insect screen
Figure 3 Multi-span greenhouse in southeastern Spain

\subsubsection{LAI}

The evolution of the LAI was determined with an electronic planimeter. Five randomly selected plants were removed for destructive sampling. In addition, any leaves removed during cultivation activities that might have affected the final index value, such as auxiliary shoots and leaf pruning, were measured. The LAI for the day was calculated by interpolation. In future, a growth model will be introduced to the temperature estimation.

\subsection{Calibration method}

Based on energy balance, a temperature simulation model was established taking into account solar radiation, heat transfer by convection with the soil surface, the cover, the back wall and different heating systems, the heat transfer between the different soils and the backwall layer as well as convection between the inside and outside air, the heat exchange with the outside air due to natural ventilation and infiltration, and the latent heat produced from crop transpiration. Once the model was decided, the different parameters of the Equations (1) were estimated in two steps: (i) The search space of the physical sensor parameters was determined using an iterative sequential algorithm to minimize a Minimal Mean Square Error (MMSE) criterion between the real and the estimated water content (sequential iterative algorithms); and (ii) a calibration process was carried out based on genetic algorithms.

The model equations were solved with Matlab/Simulink. Measured data of outdoor climate conditions and control valve settings were used as model inputs. Finally, a MMSE criterion was defined to evaluate the model parameter fix and the model performance.

\section{Results and discussion}

This paper presents a temperature model based on energy balances for two different types of greenhouse - a classical greenhouse in Almeria (Spain) and a solar greenhouse in Beijing (China). The model provides a good basis for future research and development. The calibration and validation processes were performed by adjusting parameters and functions to the production conditions that might be considered representative in the south-eastern part of the Iberian Peninsula and the northern part of China, both for experimental conditions and real data, 40320 and 3840 climate data for Almeria and Beijing, respectively. In this work, different types of climate sensor were used to take measurements of internal and external greenhouse conditions; in all cases, the data were tested to check for reliability. Furthermore, the calibration and validation data come from different time periods. This means that the climate data are very different from each other, and therefore the model's response to different climatic conditions is well-represented. Nonetheless, the model was modified based on the conditions founds in each greenhouse, adding new equations when necessary. The different equations were introduced in an ad hoc fashion, relying on a priori system knowledge. The meteorological data used in this work were gathered from both greenhouses at different times. 
Figures 4 and 5 show the estimated and measured temperature dynamics taken over five days as examples. This relates to the estimated virtual sensor values and the measured water content under different conditions. The results show how the model exhibits good behavior in both the Almeria and the Beijing greenhouses. Even when the system is under continual flux from disturbances, it is noticeable that the model captures all the resultant temperature changes. In general terms, the validation carried out gave satisfactory results, since the model demonstrated acceptable behavior during both daylight and nocturnal periods; it even presented correspondingly good dynamics when the changes were greater.

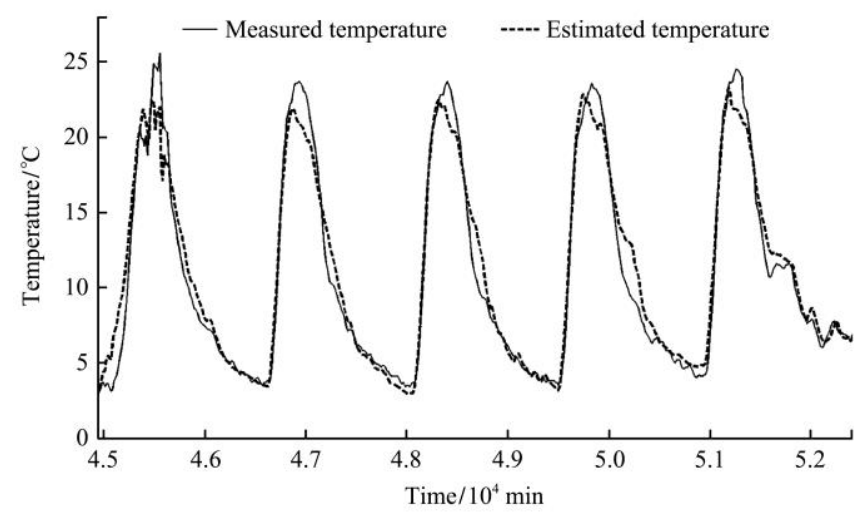

Figure 4 Temperature model tested in Spain

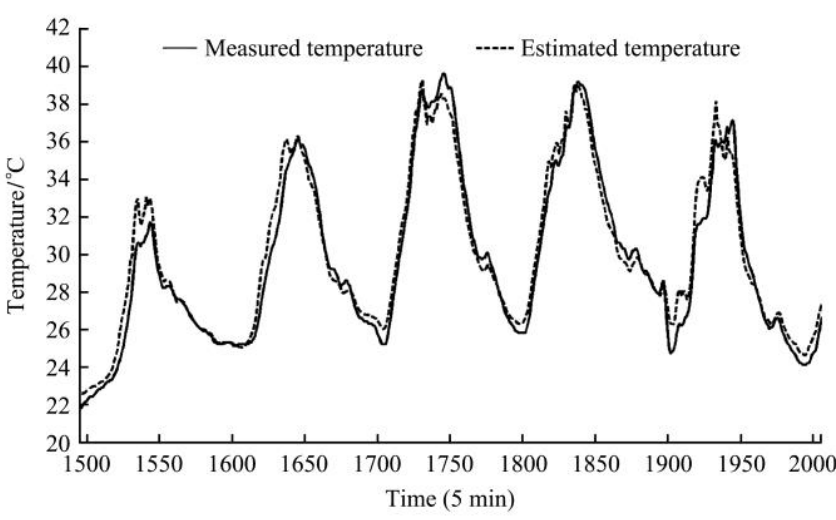

Figure 5 Temperature model tested in China

Furthermore, Figures 6 and 7 contain the errors obtained between the simulations from both greenhouses and the measured data. The goodness-of-fit for the two time series, 40320 and 3840 climate data for Almeria and Beijing, respectively, is calculated using the mean absolute error (MAE), $R^{2}$, adjusted $R^{2}$ and the root-mean-square error (RMSE).

In all cases, the model obtained good results for the Spanish and Chinese greenhouses: an MAE of 0.71 and 0.62 , an $R^{2}$ of 0.9426 and 0.9502 , an adjusted $R^{2}$ of
0.9425 and 0.9502 and an RMSE of 1.365 and 1.102, respectively; these can be seen from the validation resume in Table 1.

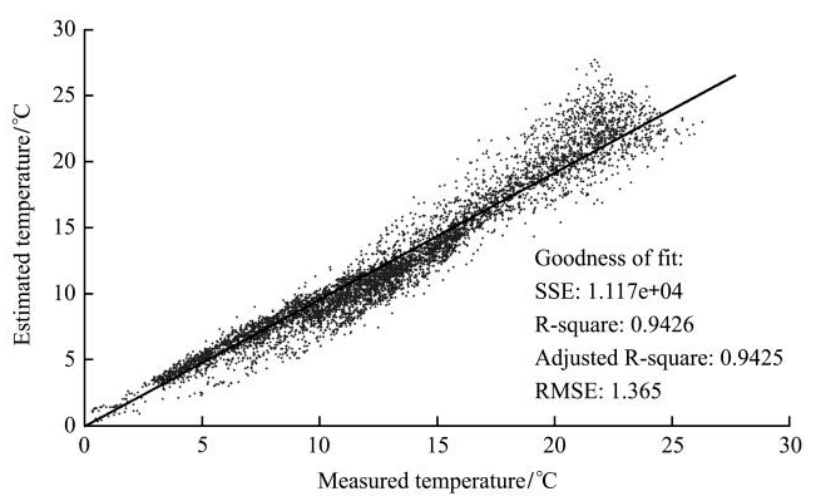

Figure 6 Linear regression with data from south-eastern Spain

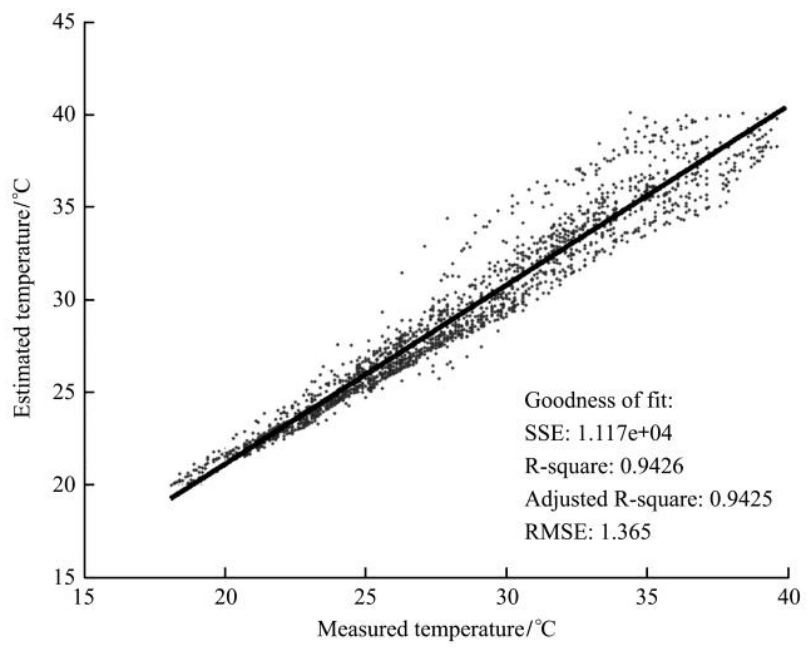

Figure 7 Linear regression with data from northern China

Table 1 Model error validation

\begin{tabular}{ccccccc} 
Localization & MAE & $R^{1}$ & $R^{2}$ adj. & RMSE & Max error & Intercal \\
\hline Almeria & 0.71 & 0.9426 & 0.9425 & 1.365 & 4.01 & {$[0.3,27.09]$} \\
Beijing & 0.62 & 0.9502 & 0.9502 & 1.102 & 3.12 & {$[18.1,39.09]$} \\
\hline
\end{tabular}

As can be observed, the average error was low, which allows us to conclude that the proposed model can be utilized to obtain acceptable temperature estimations for multispan greenhouses in very different locations around the world, each subject to different climatic conditions. The Almeria and Beijing model performed well in estimating the greenhouse air temperature - obtaining results with a good fit, as shown in Table 1. The data obtained over two different seasons were used to calibrate and validate the model. The temperature data obtained were checked with real data from both locations using linear regression, and the resulting adjustment gave a high $R^{2}$ value ( 0.94 for Beijing and 0.95 for Almeria).

In general term, the two different validations presented 
satisfactory results since the different estimated values exhibited acceptable behavior during these periods. The temperature showed little variation day-to-day, the average error was low, of which the MAE and RMSE were 0.71 and 1.365 for Almeria, and 0.62 and 1.102 for Beijing, respectively, with a maximum error of 4.01 for Almeria and 3.12 for Beijing, respectively, which also presented good dynamics, improving the goodness (MAE of 0.93 ) obtained by the previous model ${ }^{[1]}$ for an Almería-type greenhouse. Furthermore, the current models improved the results of another authors ${ }^{[7]}$ estimated the greenhouse temperature in different localizations (Sicily, The Netherlands, and in Texas and Arizona in the USA), obtained a relative root-mean-square error (RRMSE) between 4.9 and 6.4 for a full season, being the RRMSE of 4.4 for Almeria and 3.8 for Beijing, respectively. Thus, the resulting models are considered powerful tools to manage climate system design. This paper has dealt with temperature, in terms of energy balance, from an industrial point of view, considering it as a process in which there are inputs and outputs. The crop itself, and some aspects of the climate within the greenhouse, are considered as disturbances which affect the dynamics.

The model provides a good basis for future research and development. The calibration and validation processes were performed by adjusting parameters and functions to the production conditions that might be considered representative in the south-eastern part of the Iberian Peninsula and the northern part of China. Furthermore, the calibration and validation data come from different time periods. This means that the climate data are very different from each other, and therefore the model's response to different climatic conditions is well-represented. Nonetheless, the model was modified based on the conditions founds in each greenhouse, adding new equations when necessary.

\section{Conclusions}

This research presents a temperature model for two different types of greenhouse, classical greenhouses from Almería (Spain) and Beijing (China) based on energy balances. The model provides a good basis for further research and development in future. The calibration and validation processes were performed by adjusting parameters and functions to the production conditions that might be considered representative in the south-eastern part of the Iberian Peninsula and north part of China, both in experimental conditions and real data, 40320 and 3840 climate data for Almería and Beijing respectively. For this work, different climate sensor types were used to take measurements of greenhouse internal and external conditions, in all the cases the data were tested to check the reliability of the data obtained. Furthermore, the calibration and validation data belong to different period. This means that the climate data are very different to each other, and therefore the model response to different climatic conditions is well-represented. Nonetheless, the model was modified in functions of the conditions found in each greenhouse, adding new equations when it was necessary, obtaining the following conclusions:

1) The Almería and Beijing's model demonstrated good performance in the estimation of the greenhouse air temperature obtaining good fitting results. The data obtained in two different seasons were used to calibrate and validate the model.

2) The temperature data obtained were checked with real data from both localizations through linear regression and the resulting adjustment gave a high $R^{2}$ value $(0.94$ for Beijing and 0.95 for Almería).

Two different validations have been presented with satisfactory results in general terms, since the different estimated value exhibited acceptable behavior during these periods. The temperature showed little variation day-to-day, the average error was low (the MAE and RMSE were 0.71 and 1.365 for Almería; and 0.62 and 1.102 for Beijing), the maximum error was 4.01 and 3.12 for Spain and China respectively, and also presenting good dynamics. Thus, the resulting models are considered as powerful tools for control design purposes in climate systems.

This study has dealt with the temperature as energy balance from an industrial point of view, as a process in which there are entries and outputs. The crop itself, and some aspects of the climate inside the greenhouse, are considered as disturbances which affect the dynamics. 


\section{Acknowledgments}

This work has been developed within the framework of the Project IoF2020-Internet of Food and Farm 2020, funded by the Horizon 2020 Framework Programme of the European Union, Grant Agreement no. 731884, by the Spanish Ministry of Science and Innovation as well as from EUERDF funds under grant DPI2014-56364-C2-1-R, by TEAP project supported by the Marie Curie Actions (PIRSES-GA- 2013-612659, by National Natural Science Foundation of China (31401683), by Climate Change Special Founding (CCSF201521), China Meteorological Administration, and by International Cooperation Funding of Beijing Academy of Agricultural and Forestry Sciences (GJHZ2013-4).

\section{Variables, parameter values and units}

\begin{tabular}{|c|c|c|}
\hline Symbols & Units & Description \\
\hline$c_{A}$ & - & Empirical parameter \\
\hline$c_{\text {area,cv }}$ & $\mathrm{m}^{2}$ & Cover area \\
\hline$c_{\text {area }, s}$ & $\mathrm{~m}^{2}$ & Greenhouse area \\
\hline$c_{\text {area,ss }}$ & $\mathrm{m}^{2}$ & Soil surface area \\
\hline$c_{\text {area,heat }}$ & $\mathrm{m}^{2}$ & Pipe surface area \\
\hline$c_{a s w, c v}$ & $\mathrm{~W} / \mathrm{m}^{2}$ & Short-wave radiation absorptivity \\
\hline$c_{B}$ & $\mathrm{~kg} /\left(\mathrm{m}^{2} \cdot \mathrm{h} \cdot \mathrm{kPa}\right)$ & Empirical parameter \\
\hline$c_{c a l, e f}$ & $\%$ & Heating efficiency \\
\hline$c_{c n d, s l}$ & $\mathrm{~W} / \mathrm{m}^{2}$ & First soil layer heat conductivity \\
\hline$c_{\text {cnd,wall } 1}$ & $\mathrm{~W} / \mathrm{m}^{2}$ & First wall layer heat conductivity \\
\hline$c_{c n v, c v-a X}$ & $\mathrm{~W} /\left(\mathrm{m}^{2 \cdot \mathrm{K}}\right)$ & Empirical parameter \\
\hline$c_{c n v, s s-a X}$ & $\mathrm{~W} /\left(\mathrm{m}^{2 \cdot \mathrm{K}}\right)$ & Empirical parameter \\
\hline$c_{c n v, \text { wall-aX }}$ & $\mathrm{W} /\left(\mathrm{m}^{2 \cdot \mathrm{K}}\right)$ & Empirical parameter \\
\hline$c_{d e n, a}$ & $\mathrm{~kg} / \mathrm{m}^{3}$ & Air density \\
\hline$c_{d, s s}$ & $\mathrm{~m}$ & Soil surface depth \\
\hline$c_{d, s l}$ & $\mathrm{~m}$ & First soil layer thickness \\
\hline$c_{d, \text { wall }}$ & $\mathrm{m}$ & Wall surface depth \\
\hline$c_{d, \text { wall } 1}$ & $\mathrm{~m}$ & Wall layer thickness \\
\hline$c_{d e n, c v}$ & $\mathrm{~kg} / \mathrm{m}^{3}$ & Cover material density \\
\hline$c_{\text {loss,lw }}$ & $\mathrm{m}^{3 / \mathrm{s}}$ & Leakage with low wind speed \\
\hline$c_{l o s s, h w}$ & $\mathrm{~m}^{3 / \mathrm{s}}$ & Leakage with high wind speed \\
\hline$c_{g v}$ & $\mathrm{~m} / \mathrm{s}^{2}$ & First soil layer thickness \\
\hline$c_{k}$ & - & Empirical coefficient \\
\hline$c_{s p h, a}$ & $\mathrm{~J} /\left(\mathrm{kg}^{\cdot \mathrm{k})}\right.$ & Specific air heat \\
\hline$c_{s p h, c v}$ & $\mathrm{~J} /\left(\mathrm{kg}^{\cdot \mathrm{k})}\right.$ & Cover material specific heat \\
\hline$c_{v e n, h}$ & $\mathrm{~m}$ & lateral and roof vent distance \\
\hline$c_{v e n, d}$ & $\mathrm{~m}^{3 / \mathrm{s}}$ & Discharge coefficient \\
\hline$c_{\text {ven }, l}$ & $\mathrm{~m}$ & vent length \\
\hline$c_{\text {ven,long-lat }}$ & $\mathrm{m}$ & lateral length, respectively \\
\hline$c_{\text {ven,long-roof }}$ & $\mathrm{m}$ & Roof length,respectively \\
\hline
\end{tabular}

\begin{tabular}{|c|c|c|}
\hline Symbols & Units & Description \\
\hline$c_{v e n, n}$ & units & Number of vents \\
\hline$c_{v e n, w}$ & $\mathrm{~m}$ & Vent width \\
\hline$c_{\text {ven,wd }}$ & $\mathrm{m} / \mathrm{s}$ & Wind effect coefficient \\
\hline$c_{\text {ven,wid-lat }}$ & $\mathrm{m}$ & lateral width \\
\hline$c_{\text {ven, wid-roof }}$ & $\mathrm{m}$ & Roof width \\
\hline$c_{v o l, c v}$ & $\mathrm{~m}^{3}$ & Cover volume \\
\hline$c_{v o l, g}$ & $\mathrm{~m}^{3}$ & Greenhouse volume \\
\hline$c_{w s, l i m}$ & $\mathrm{~m} / \mathrm{s}$ & Wind speed limit considered \\
\hline$D_{t, t}$ & $\mathrm{~m} / \mathrm{s}$ & External wind speed \\
\hline$M_{\text {evp,ss }}$ & $\mathrm{kg} /(\mathrm{W} \cdot \mathrm{s})$ & Soil surface mass evaporation flux \\
\hline$Q_{\text {calen }}$ & $\mathrm{kW}$ & Nominal energy of heating system \\
\hline$Q_{c d, c v}$ & $\mathrm{~J} / \mathrm{kg}$ & Latent heat by condensation \\
\hline$Q_{\text {cnv,aero-a }}$ & $\mathrm{W} /(\mathrm{m} \cdot \mathrm{K})$ & Heat fluxes with the heating pipes \\
\hline$Q_{c n d, c v}$ & $\mathrm{~W} /(\mathrm{m} \cdot \mathrm{K})$ & Conduction heat flux \\
\hline$Q_{c n v, c v-a}$ & $\mathrm{~m}^{3 / \mathrm{s}}$ & Conduction flux with the cover \\
\hline$Q_{c n v, e}$ & $\mathrm{~W} /(\mathrm{m} \cdot \mathrm{K})$ & Outside-air convective transfer \\
\hline$Q_{c n v, \text { heat-a }}$ & $\mathrm{W} /(\mathrm{m} \cdot \mathrm{K})$ & Aerothermal heating heat fluxes \\
\hline$Q_{c n v, s s-a}$ & $\mathrm{~W} /\left(\mathrm{m}^{2} \mathrm{~K}\right)$ & Convective flux with the soil \\
\hline$Q_{\text {evp,ss }}$ & $\mathrm{J} / \mathrm{kg}$ & Latent heat flux in the soil \\
\hline$Q_{r a d, c v}$ & $\mathrm{~W} / \mathrm{m}^{2}$ & Thermal radiation absorbed by the cover \\
\hline$Q_{s o l, c v}$ & $\mathrm{~W} / \mathrm{m}^{2}$ & Solar radiation absorbed by the cover \\
\hline$Q_{v e n}$ & $\mathrm{~W} /\left(\mathrm{m}^{2} \mathrm{~K}\right)$ & Heat flux by natural ventilation \\
\hline$Q_{t r p, c r}$ & Crop & transpiration latent heat effect \\
\hline$Q_{c n v, w a l l-a}$ & $\mathrm{~W} /\left(\mathrm{m}^{2} \mathrm{~K}\right)$ & Convective flux with the back wall \\
\hline$U_{a c, h e a t}$ & $\%$ & Heater activation control signal \\
\hline$U_{t, \text { heat }}$ & $\mathrm{K}$ & Water temperature in the heating pipes \\
\hline$U_{\text {ven }}$ & $\%$ & Ventilation position \\
\hline$V_{\text {ven,area-lat }}$ & $\mathrm{m}^{2}$ & Sidewall ventilation area \\
\hline$V_{\text {ven, area-roof }}$ & $\mathrm{m}^{2}$ & Roof ventilation area \\
\hline$V_{c n v, c v-a}$ & $\mathrm{~W} /\left(\mathrm{m}^{2} \mathrm{~K}\right)$ & Cover inside convective heat transfer \\
\hline$V_{c n v, h e a t-a}$ & $\mathrm{~W} /\left(\mathrm{m}^{2} \mathrm{~K}\right)$ & Heating convective coefficient \\
\hline$c_{c n v, \text { heat-aX }}$ & - & Empirical parameters \\
\hline$V_{c n v, s s-a}$ & $\mathrm{~W} /\left(\mathrm{m}^{2} \mathrm{~K}\right)$ & Soil surface convective coefficient \\
\hline$V_{c n v, \text { wall-a }}$ & $\mathrm{W} /\left(\mathrm{m}^{2} \mathrm{~K}\right)$ & Back wall convective coefficient \\
\hline$V_{\text {hsat,ss }}$ & $\mathrm{kg}_{\text {water }} \mathrm{kg}_{\text {soil }}$ & Water concentration at saturation \\
\hline$V_{\text {loss }}$ & $\mathrm{m}^{3} / \mathrm{s}$ & Leakage when the vent is closed \\
\hline$V_{l t, v a p}$ & $\mathrm{~J} / \mathrm{kg}$ & Latent heat of evaporation \\
\hline$V_{\text {texh }, a}$ & $\mathrm{~m}^{3} / \mathrm{s}$ & Exhaust air temperature \\
\hline$V_{V P D}$ & $\mathrm{kPa}$ & Vapour pressure deficit \\
\hline$V_{\text {vent,flow }}$ & $\mathrm{m}^{3} / \mathrm{s}$ & Volumetric flow rate \\
\hline$V_{\text {ven,hef }}$ & $\mathrm{m}$ & joining the two vents \\
\hline$V_{\text {ven, reg }}$ & $\mathrm{m}^{3} / \mathrm{s}$ & Ventilation regime coefficient \\
\hline$V_{w s, a}$ & $\mathrm{~m} / \mathrm{s}$ & Mean greenhouse air speed \\
\hline$X_{\text {LAI }}$ & $\mathrm{m}^{2} / \mathrm{m}^{2}$ & Leaf Area Index \\
\hline$X_{t, a}$ & K & Air temperature \\
\hline$X_{t, c v}$ & K & Cover temperature \\
\hline$X_{t, s s}$ & $\mathrm{~K}$ & Soil surface temperature \\
\hline$X_{t, s 1}$ & $\mathrm{~K}$ & Soil first layer temperature \\
\hline$X_{t, \text { wall } 1}$ & $\mathrm{~K}$ & Wall surface temperature \\
\hline$X_{t, \text { wall } 1}$ & $\mathrm{~K}$ & Wall first layer temperature \\
\hline
\end{tabular}




\section{[References]}

[1] Rodriuez F, Berenguel M, Guzman J L, Ramiez-Arias A. Modeling and control of greenhouse crop growth. Springer International Publishing Switzerland, 2015.

[2] Ramiez-Arias A, Rodriuez F, Guzman J L, Berenguel M. Multiobjective hierarchical control architecture for greenhouse crop growth. Automatica, 2012; 48(3): 490-498.

[3] Matysiak B, Nowak J. Carbon dioxide and light effects on photosynthesis, transpiration and ex vitro growth of Homalomena 'Emerald Gem' plantlets. SciHorticAmsterdam, 1994; 57(4): 353-358.

[4] Seginer I, Boulard T, Bailey B J. Neural network models of the greenhouse climate. J Agr Eng Res, 1994; 59: 203-216.

[5] Ramiez-Arias J A. Hierarchical multiobjective control of greenhouse crop production. University of Almeria, 2005. (in Spanish)

[6] Van Straten G. Optimal Control of Greenhouse Cultivation. CRC Press, Boca Raton, FL, USA. 2011, 328.

[7] Vanthoor B H E, Stanghellini C, van Henten E J, de Visser P H B. A methodology for model-based greenhouse design: Part 1, a greenhouse climate model for a broad range of designs and climates. Biosyst Eng, 2011; 110(4): 363-377.

[8] Baille M, Baille L, Laury J C. A simplified model for predicting evapotranspiration rate of nine ornamental species vs. climate factors and leaf area. Sci Hort, 1994; 59: 217-232.

[9] Curry R B. Dynamic simulation of plant growth -Part I. Development of a model. Transation of ASAE, 1971; 14(5): 946-959.

[10] Tong G H, Christopher $\mathrm{D}$ M, Li T L, Wang $\mathrm{T}$ L. Temperature variations inside Chinese solar greenhouses with external climatic conditions and enclosure materials. 2008; Int J Agric \& Biol Eng, 2012; 1(2): 21-26.

[11] Farquhar G D, Caemmerer S, Berry J A. A biochemical model of photosynthetic $\mathrm{CO}_{2}$ assimilation in leaves of $\mathrm{C} 3$ species. Planta, 1980; 1: 78-90.

[12] Jolliet O, Bailey B. The effect of climate on tomato transpiration in greenhouses: measurements and models comparison. Agr Forest Meteorol, 1992; 58: 43-62.

[13] Farzaneh-Gord M, Arabkoohsar A, Bayaz M D D, Khoshnevis A B. New method for applying solar energy in greenhouses to reduce fuel consumption. Int J Agric \& Biol Eng, 2013; 6(4): 64-75.

[14] Zhang X, Wang H L, Zou Z R, Wang S J. CFD and weighted entropy based simulation and optimisation of Chinese Solar Greenhouse temperature distribution. Biosystems Eng, 2016; 142: 12-26.

[15] Xu F, Li S, Ma C, Zhao S, Han J, Liu Y, et al. Thermal environment of Chinese solar greenhouses: analysis and simulation. Appl Eng Agr, 2013; 29(6): 991-997.

[16] Medrano E, Lorenzo P, Sachez-Guerrero M C, Montero J I. Evaluation and modelling of greenhouse cucumber-crop transpiration under high and low radiation conditions. SciHortic, 2005; 105: 163-175.

[17] Montero J, Anton A, Munoz P, Lorenzo P. Transpiration from geranium grown under high temperatures and low humidities in greenhouses. Agr Forest Meteorol, 2001: 323-332.

[18] Bakker J. Greenhouse climate control: an integrated approach. Wageningen Academic Pub, 1995.

[19] Jacobson B K, Jones P H, Jones J W, Paramore J A. Real-time greenhouse monitoring and control with an expert system. Comput Electron Agr, 1989; 3(4): 273-285.

[20] Kamp P G H, Timmerman G J. Computerized environmental control in greenhouses. A step by step approach. The Netherlands: IPC Plant, 1996.

[21] Bot G P A. Greenhouse climate: from physical process to a dynamic model. Universidad de Wageningen, Holanda, 1983.

[22] Boulard T, Baille A. Modelling of Air Exchange Rate in a Greenhouse Equipped with Continuous Roof Vents. J Agr Eng Res, 1995; 61(1): 37-48.

[23] Frace J, Thornley J M H. Mathematical models in agriculture. London Butterworths, 1984. 620.

[24] Rodriguez F, Guzman J L, Berenguel M, Arahal M R. Adaptive hierarchical control of greenhouse crop production. Int J Adapt Control, 2008; 22: 180-197.

[25] Sanchez-Molina J A, Rodriguez F, Guzman J L, Fernandez M D, Arahal M R. Modelling of tomato crop transpiration dynamics for designing new irrigation controllers. Acta Hortic, 2011; 893: 729-738.

[26] Ji Y H, Jiang Y Q, Li T, Zhang M, Sha S, Li M Z. An improved method for prediction of tomato photosynthetic rate based on WSN in greenhouse. Int J Agric \& Biol Eng, 2016; 9(1): 146-152.

[27] Marcelis L F M, Buwalda F, Dieleman J A, Dueck T A, Elings A, de Gelder A, et al. Innovations in crop production A matter of physiology and technology. Acta Hortic, 2014; 1037: 39-46.

[28] Sanchez-Molina J A, Rodriguez F, Guzman J L, Acien F G, Lopez J C. Strategies for control of temperature by increasing the concentration of $\mathrm{CO}_{2}$ by burning in cultivation under plastic. V Congreso Iberico de AgroIngenieria. Lugo, Spain, 2009.

[29] Kittas C, Boulard T, Papadakis G. Natural ventilation of a greenhouse with ridge and side openings: Sensitivity to temperature and wind effects. Transactions of ASAE, 
1997; 40(2): 415-425.

[30] Sanchez-Molina J A, Rodriguez F, Guzman J L, Arahal M R. Virtual sensors for designing irrigation controllers in greenhouses. Sensors-Basel, 2012; 11: 15244-15266.

[31] Ha T, Lee I B, Kwon K S, Hong S W. Computation and field experiment validation of greenhouse energy load using Building Energy Simulation model. Int J Agric \& Biol Eng, 2015; 8(6): 116-127.

[32] Wan-Liang W, Qi-Di W. Neural network modelling and intelligence control of the distributed parameter greenhouse climate. 14th IFAC World Congress Beijing, China,
1999; 1: 479-484.

[33] ASAE. Heating, ventilating, and cooling greenhouses (EP406.3). American Society of Agricultural Engineering Standards. Michigan. USA, 1998.

[34] Flores-Velazquez J, Montero J I, Baeza E J, Lopez J C. Mechanical and natural ventilation systems in a greenhouse designed using computational fluid dynamics. Int J Agric \& Biol Eng, 2014; 1(7): 1-16.

[35] Seginer I. Some artificial neural network applications to greenhouse environmental control. Comput Electron Agr, 1997; 18: 167-186. 